\title{
Water Hammer Modelling and Simulation by GIS
}

\author{
K. Hariri Asli, ${ }^{1}$ A. K. Haghi, ${ }^{2}$ H. Hariri Asli, ${ }^{3}$ and E. Sabermaash Eshghi ${ }^{4}$ \\ ${ }^{1}$ Department of Mathematics and Mechanics, National Academy of Science of Azerbaijan, 41886-13133 Baku, Azerbaijan \\ ${ }^{2}$ College of Engineering, University of Guilan, Rasht 3756-41635, Iran \\ ${ }^{3}$ Department of Civil Engineering, Applied Science and Technology University, Rasht 41886-14618, Iran \\ ${ }^{4}$ Faculty of Entrepreneurship, University of Tehran, Tehran 14155-6311, Iran
}

Correspondence should be addressed to K. Hariri Asli, hariri_k@yahoo.com

Received 20 April 2012; Accepted 14 June 2012

Academic Editor: Laurent Mevel

Copyright () 2012 K. Hariri Asli et al. This is an open access article distributed under the Creative Commons Attribution License, which permits unrestricted use, distribution, and reproduction in any medium, provided the original work is properly cited.

This work defined an Eulerian-based computational model compared with regression of the relationship between the dependent and independent variables for water hammer surge wave in transmission pipeline. The work also mentioned control of Unaccounted-for-Water (UFW) based on the Geography Information System (GIS) for water transmission pipeline. The experimental results of laboratory model and the field test results showed the validity of prediction achieved by computational model.

\section{Introduction}

Water hammer phenomena occurring during water hammer are explained on the basis of compressibility of liquid. Many researchers have made significant contributions in this area. Zhukovsky introduced the concept of the effective sound speed. He mentioned reducing the motion of a compressible fluid in an elastic cylindrical pipe to the motion of a compressible fluid in a rigid pipe, but with a lower modulus of elasticity of the liquid. Subjects of transients in liquids are still growing fast around the world. Scientists have developed various methods of investigation of transient pipe flow. These ranges of methods are included by approximate equations to numerical solutions of the nonlinear NavierStokes equations. They obtained the differential equations of motion of inviscid fluid forming the basis for further development of the theory of pressure and pressure flow of viscous fluid. By helping of this theory, it became possible to explain of the physical phenomenon, known as water hammer. They introduced the concept of the effective sound speed. Therefore transient flow was solved for the pipeline in the range of approximate equations. These approximate equations are solved by numerical solutions of the nonlinear Navier-Stokes equations in a method of characteristics (MOC). So, experiences are ensured for the reliable water transmission pipeline. Numerical modeling and simulation which are defined by method of characteristics (MOC) provides a set of results. The (MOC) approaches transform the water hammer partial differential equations into the ordinary differential equations along the characteristic lines defined as the continuity equation, and the momentum equation are needed to determine $V$ and $P$ in a one-dimensional flow system. Solving these two equations produces a theoretical result that usually corresponds quite closely to actual system measurements based on Geography Information System (GIS) if the data and assumptions used to build the (GIS) already are valid.

Curve estimation for the experimental results of laboratory model and the field test results is the most appropriate when the relationship between the dependent variable and the independent variable is not necessarily linear. Linear regression is used to model the value of a dependent scale variable based on its linear relationship to one or more predictors. Nonlinear regression is appropriate when the relationship between the dependent and independent variables is not intrinsically linear. Binary logistic regression is most useful in modeling of the event probability for a categorical response variable with two outcomes. The autoregression procedure is an extension of ordinary least-squares regression analysis specifically designed for time series. One of the assumptions underlying ordinary least-squares regression is the absence of autocorrelation in the model residuals. Time 
series, however, often exhibit first-order autocorrelation of the residuals. In the presence of autocorrelated residuals, the linear regression procedure gives inaccurate estimates of how much of the series variability is accounted for by the chosen predictors. This can adversely affect the choice of predictors, and hence the validity of the model [1].

\section{Materials and Methods}

A GIS ready model for liquid-vapor flows illustrates the numerical techniques for solving the resulting equations. Hence field test model was chosen for experimental presentation of water hammer phenomenon at the water pipeline:

$$
\begin{gathered}
\frac{d V}{d t}+\frac{1}{\rho} \cdot \frac{\partial P}{\partial S}+g \frac{d Z}{d S}+\frac{f}{2 D} V|V|=0 \quad \text { (Euler equation) } \\
C^{2} \frac{\partial V}{\partial S}+\frac{1}{\rho} \cdot \frac{d \rho}{d t}=\circ \quad \text { (Continuity equation). }
\end{gathered}
$$

Partial differential equation (1) are solved by method of characteristics MOC.

The method of characteristics is a finite difference technique in which pressures were computed along the pipe for each time step.

Calculation automatically subdivided the pipe into sections (intervals) and selected a time interval for computations; equations are the characteristic equations (2), (4).

$$
\begin{gathered}
\frac{d V}{d t}-\frac{g}{c} \cdot \frac{d H}{d t}=\circ \quad \text { or } \\
d H=\left(\frac{C}{g}\right) d V \quad \text { (Zhukousky). }
\end{gathered}
$$

If the pressure at the inlet of the pipe and along its length is equal to $p_{0}$, then slugging pressure undergoes a sharp increase:

$$
\Delta p: p=p_{0}+\Delta p
$$

The Zhukousky formula is as flows:

$$
\Delta p=\left(\frac{C \cdot \Delta V}{g}\right) \text {. }
$$

The speed of the shock wave is calculated by the formula:

$$
C=\sqrt{\frac{g \cdot\left(E_{W} / \rho\right)}{1+\left(d / t_{W}\right) \cdot\left(E_{W} / E\right)}} .
$$

For the velocity of surge or pressure wave in an elastic case with low value of free water bubble, the equation (6) would be valid:

$$
C=\frac{1}{\left[\rho\left(\left(1 / E_{W}\right)+\left(D / E \cdot t_{W}\right)+(n / P)\right)\right]^{1 / 2}} .
$$

The velocity of pressure wave (7) in an elastic case with the high value of free water bubble is presented by the flowing equation $[2,3]$ :

$$
C=\left(\frac{g \cdot h}{n}\right)^{1 / 2}
$$

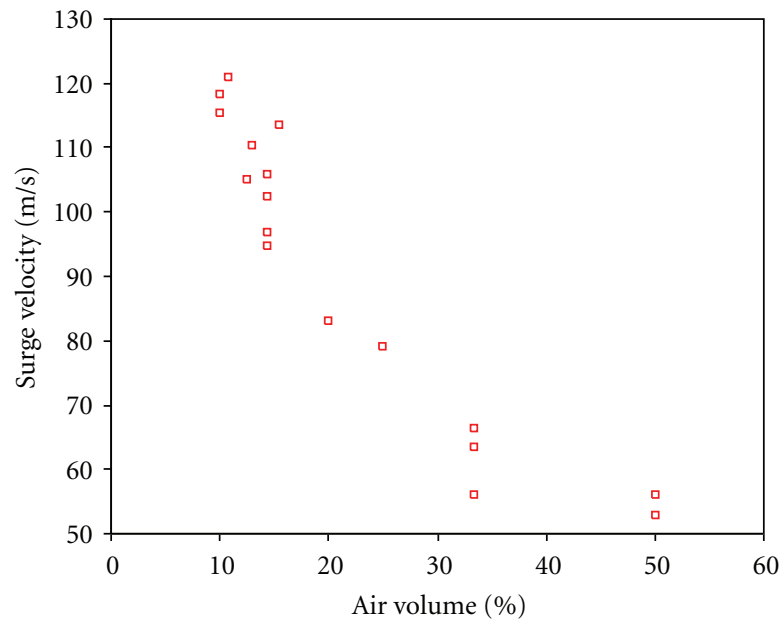

FIGURE 1: 2-D scatter diagram of surge wave speed for water pipeline with free water bubble.

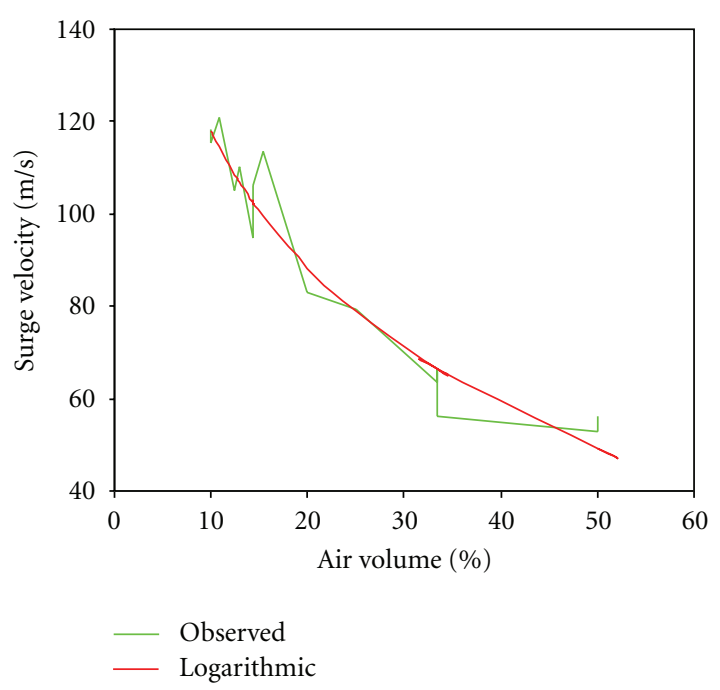

FIgURE 2: Logarithmic curve fit for surge wave speed of water pipeline with free water bubble.

2.1. Regression Model due to Field Test for Surge Wave Velocity. The autoregression procedure accounts for firstorder autocorrelated residuals. It provides reliable estimates of both goodness-of-fit measures and significant levels of chosen predictor variables.

The variables are as follows: $C$-velocity of surge wave $(\mathrm{m} / \mathrm{s})$ as a dependent variable with nomenclature " $Y$," independent variable with nomenclature " $X$ " such as $n-$ percent of air volume $\left(\mathrm{m}^{3}\right)$. The curve estimation procedure allows quick estimating regression statistics, and producing related plots for different models. Hence the autoregression procedure by regression software "SPSS 10.0.5" was selected for the curve estimation procedure in the present work. The regression model has been built based on field test data.

Regression software "SPSS" has fitted the function curve and provided regression analysis. So, the regression model has been found in the final procedure. By this model, field 
TABLE 1: Regression for model summary.

\begin{tabular}{lcccc}
\hline Model & $R$ & $R$ square & Adjusted $R$ square & Std. error of the estimate \\
\hline 1 & $0.930^{\mathrm{a}}$ & 0.865 & 0.856 & 9.08222 \\
\hline
\end{tabular}

${ }^{a}$ Predictors: constant, air volume percent.

TABLE 2: List-wise deletion of missing data for curve fit by logarithmic method.

\begin{tabular}{lc}
\hline Multiple $R$ & 0.96799 \\
$R$ square & 0.93701 \\
Adjusted $R$ square & 0.9328 \\
Standard error & 6.20621 \\
\hline
\end{tabular}

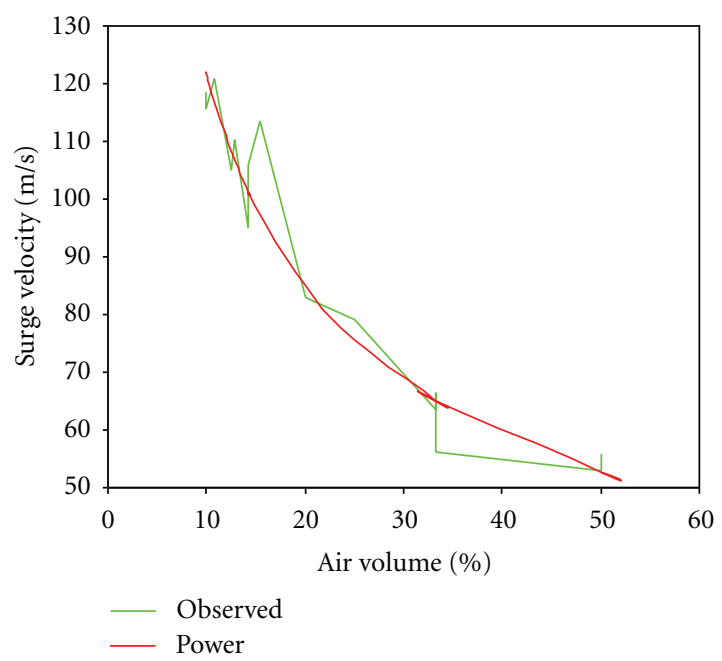

Figure 3: Power curve fit for surge wave speed of water pipeline with free water bubble.

test results have been compared by computational model results. The main practical aim of the present work was concentrated on the definition of a condition base maintenance (CM) method for all water transmission systems. In this work the data collection procedures were as follows.

At fast transients, down to 1 second, surge pressure and velocity of surge wave were recorded. These data were used for curve estimation procedure. They were detected on actual systems (field tests). Also, flow and pressure were computed by computational model. Those data have been compared with flow and pressure data which have been collected from actual systems (field tests). The model is calibrated using one set of data, without changing parameter values. It is used to match a different set of results. Curve estimation procedure is illustrated in Figures 1 and 2 for surge wave velocity was formed by estimating regression statistics which are listed in Tables 1 and 2. However, related plots for the field test model were produced [4-6].

\section{Results and Discussion}

In this work conclusions were drawn on the basis of experiments and calculations for the pipeline with a local

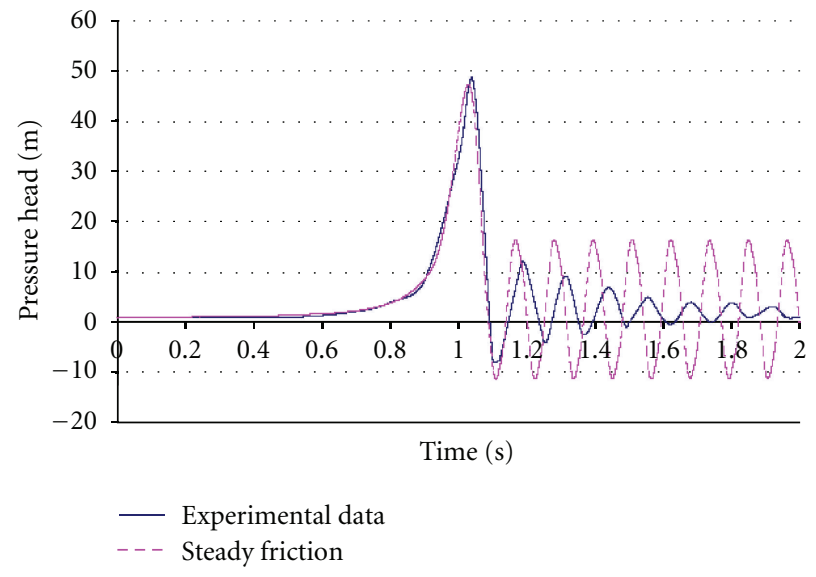

(a)

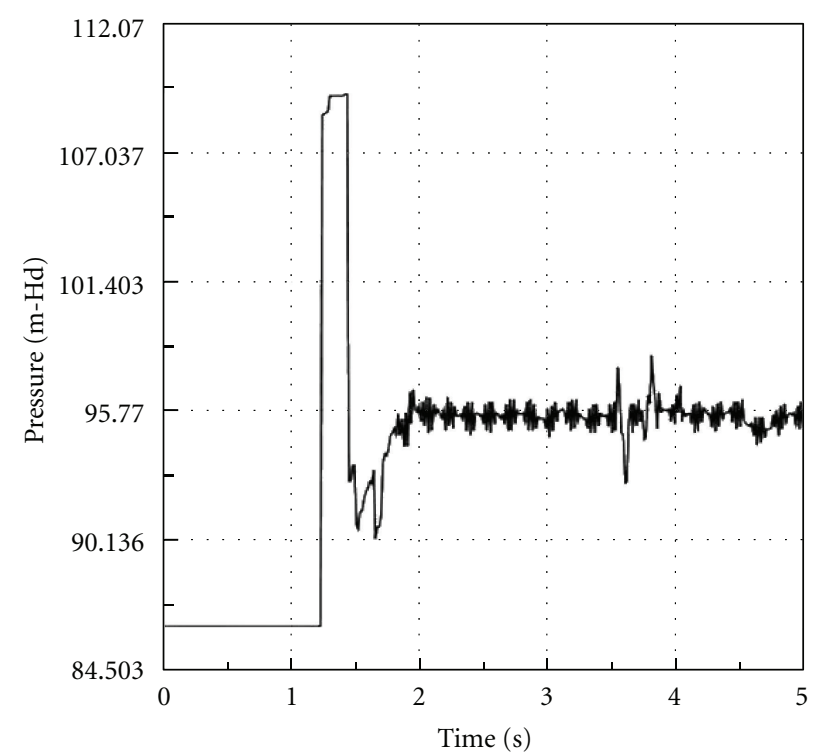

(b)

Figure 4: Pressure head histories for a single piping system using (a) steady friction and (b) steady friction.

leak. Hence, the most important effects that were observed are as follows. The pressure wave speed generated by water hammer phenomenon was influenced by some additional factors. Therefore the ratio of local leakage and discharge from the leak location was mentioned. The effect of total discharge from the pipeline and its effect on the values of wave oscillations period were studied. The outflow to the surge tank from the leak affected the value of wave celerity. The pipeline was equipped with the valve at the end of the main pipe, which was joined with the closure time register. 
The water hammer pressure characteristics were measured by extensometers.

Power functions are illustrated in Figure 3; however, a variable base is raised to a fixed exponent. The parameter $b$ 。 serves as a simple scaling factor, moving the values of $X^{b_{1}}$ up or down as $b$ 。 increases or decreases, respectively, and the parameter $b_{1}$, called either the exponent or the power, determines the function's rates of growth or decay $[7,8]$.

Chaudhry [9] obtained pressure heads by the steady model which is illustrated in Figure 4. Comparison showed similarity in present work and work of Chaudhry.

\section{Conclusions}

This work focused on the effects of the penetrated air on the surge wave velocity in water pipeline. It showed that Eulerian-based computational model is more accurate than the regression model. Hence in order to present importance of penetrated air on water hammer phenomenon, it was compared the models for laboratory; computational and field tests experiments. At these procedures, it was showed that the Eulerian based model for water transmission line. It was compared with the regression model. On the other hand, this idea were included the proper analysis to provide a dynamic response to the shortcomings of the system. It also performed the design protection equipments to manage the transition energy and determine the operational procedures to avoid transients. Consequently, the results of this work will help to reduce the risk of system damage or failure at the water pipeline.

\section{Nomenclatures}

$C:$ Velocity of surge wave $(\mathrm{m} / \mathrm{s})$

$n$ : Percent of air volume $(\mathrm{m})$

$t_{W}$ : Wall thickness of pipe $(\mathrm{mm})$

$g$ : Acceleration of gravity $(\mathrm{m} / \mathrm{s})$

$h$ : Head of the liquid (water) column, (m)

E: Modulus of elasticity for pipeline material Steel $E=10^{11}(\mathrm{~Pa}),(\mathrm{kg} / \mathrm{m})$

$d$ : Outer diameter of the pipe $(\mathrm{mm})$

$\rho: \quad$ Density $(\mathrm{kg} / \mathrm{m})$

$P$ : $\quad$ Surge pressure $(\mathrm{Pa})$

$E_{W}$ : Module of elasticity of water $(\mathrm{Pa}),(\mathrm{kg} / \mathrm{m})$

$t$ : Time $(\mathrm{S})$

$V:$ Velocity $(\mathrm{m} / \mathrm{s})$

$S: \quad$ Length $(\mathrm{m})$

$D: \quad$ Diameter of each pipe $(\mathrm{mm})$

$Z$ : Elevation head (m)

$f$ : Darcy Weishach coefficient.

\section{Acknowledgments}

The authors thank all specialists for their valuable observations and advice and the referees for recommendations that improved the quality of this paper.

\section{References}

[1] K. Hariri Asli, F. B. Nagiyev, and A. K. Haghi, "Interpenetration of two fluids at parallel between plates and turbulent moving in pipe," in Computational Methods in Applied Science and Engineering, chapter 7, pp. 115-128, Nova Science, New York, NY, USA, 2009.

[2] T. S. Lee and S. Pejovic, "Air influence on similarity of hydraulic transients and vibrations," Journal of Fluids Engineering, Transactions of the ASME, vol. 118, no. 4, pp. 706-709, 1996.

[3] K. Hariri Asli,, F. B. Nagiyev, and A. K. Haghi, "Some aspects of physical and numerical modeling of water hammer in pipelines," International Journal of Nonlinear Dynamics and Chaos in Engineering Systems, vol. 60, no. 4, pp. 677-701, 2010.

[4] K. Hariri Asli, F. B. Nagiyev, and A. K. Haghi, Physical Modeling of Fluid Movement in Pipelines, Nanomaterials Yearbook, New York, NY, USA, 2009.

[5] A. Kodura and K. Weinerowska, "The influence of the local pipeline leak on water hammer properties," Materials of the II Polish Congress of Environmental Engineering, Lublin, Poland, 2005.

[6] M. S. Ghidaoui, S. G. S. Mansour, and M. Zhao, "Applicability of quasi-steady and axisymmetric turbulence models in water hammer," Journal of Hydraulic Engineering, vol. 128, no. 10, pp. 917-924, 2002.

[7] K. Hariri Asli, "GIS and water hammer disaster at earthquake in rasht water pipeline," in Proceedings of the 3rd International Conference on Integrated Natural Disaster Management (INDM '08), Tehran, Iran, 2008, http://www.civilica.com/Paper-INDM 03-INDM03_001.html.

[8] K. Hariri Asli, "GIS and nonlinear dynamics model: some computational aspects and practical hints," International Journal on Technical and Physical Problems of Engineering, vol. 2, no. 5, pp. $1-5,2010$.

[9] M. H. Chaudhry, Applied Hydraulic Transients. Van Nostrand Reinhold, New York, NY, USA, 1987. 

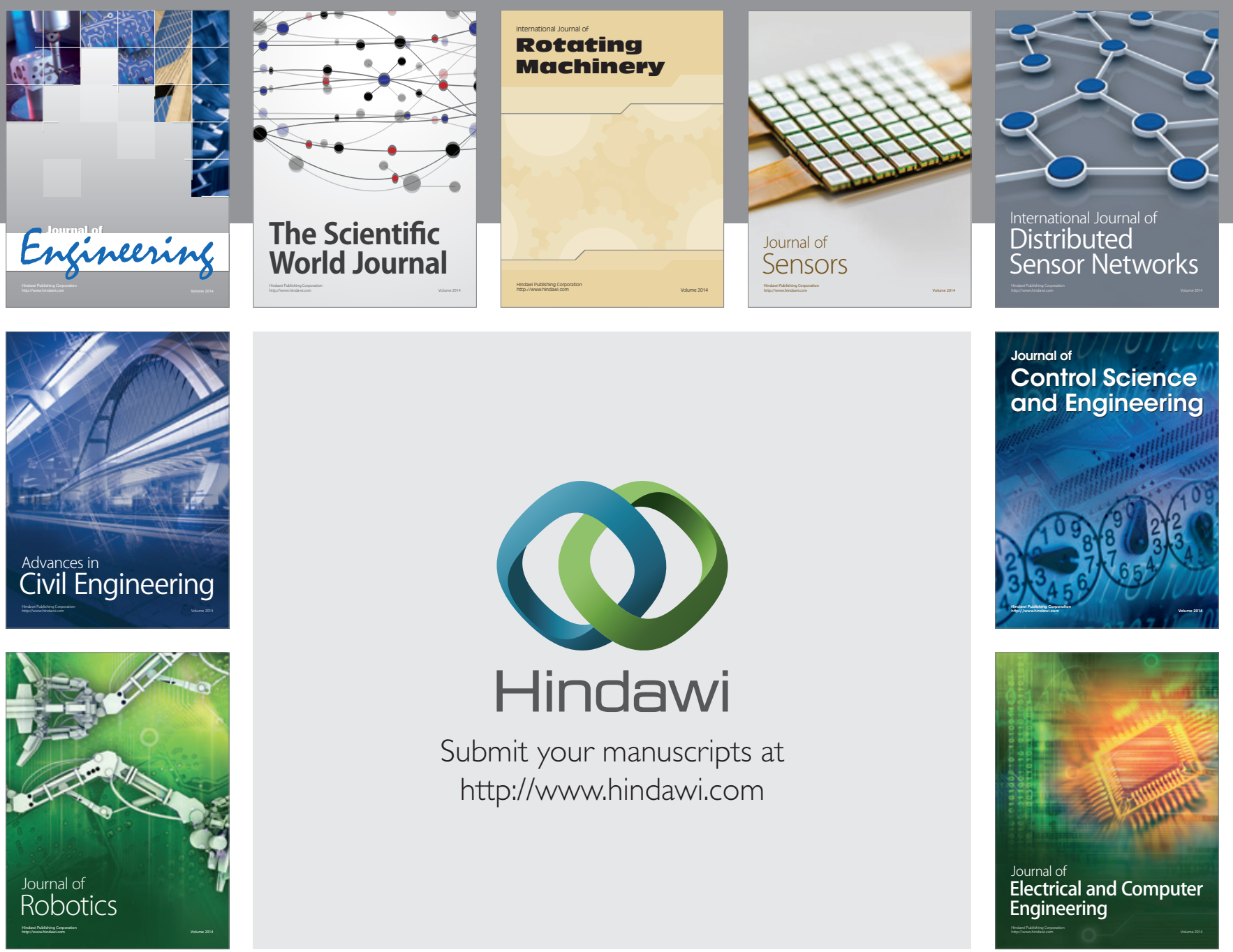

Submit your manuscripts at

http://www.hindawi.com
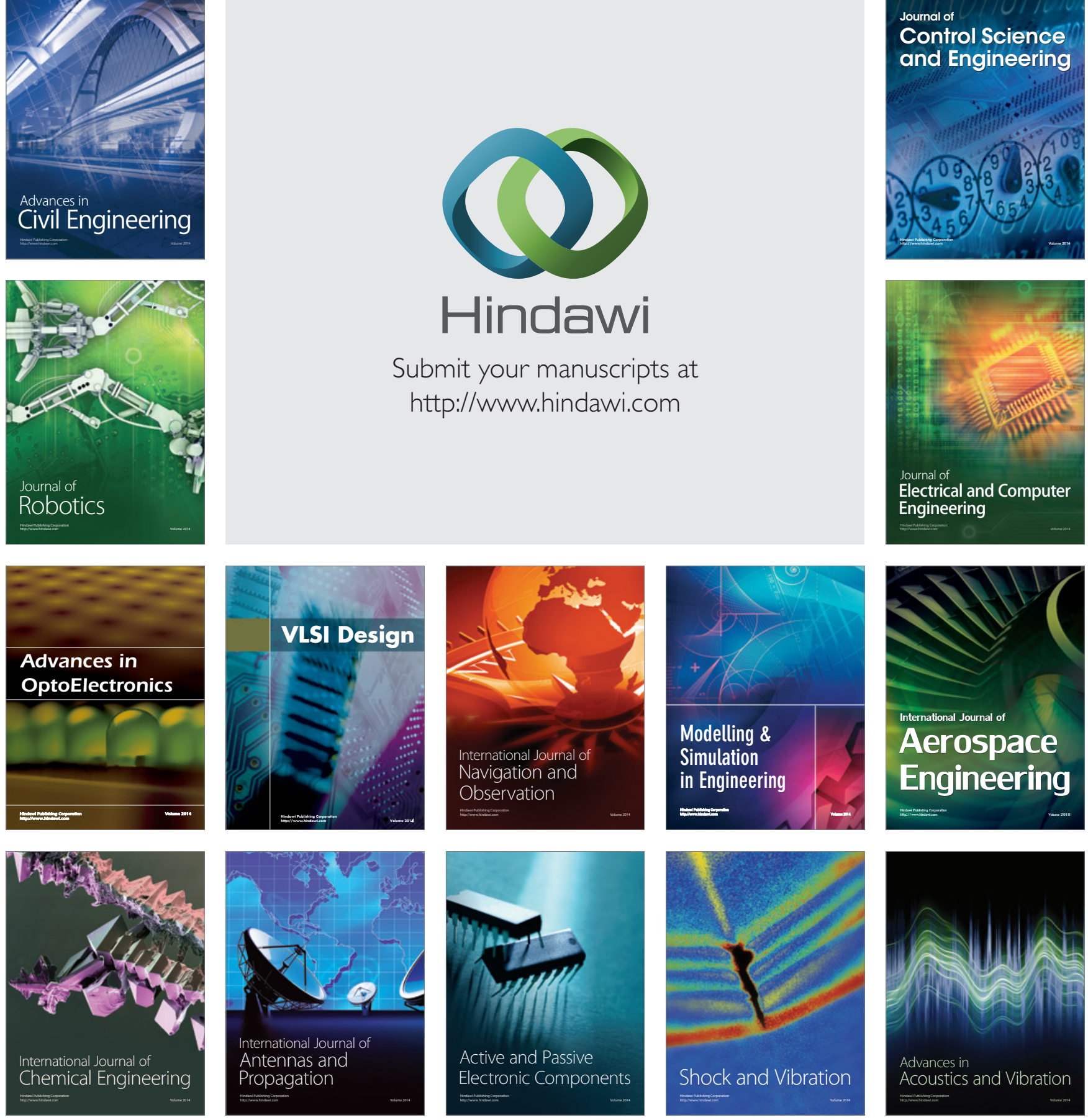